\title{
ON FINE DISTRIBUTION OF ROD DERIVED CONE VIABILITY FACTOR IN THE RABBIT RETINA
}

\author{
A.M Petrosian*, L.A. Poghosyan*, V.K. Gasparyan", M.V. Mikaelyan ${ }^{*}$, E.Clerin ${ }^{* *}$, J.A.Sahel ${ }^{* *}$, \\ T.Leveillard $^{* *}$
}

*) Buniatian Institute of Biochemistry of the NAS of Armenia, 375014, P.Sevag St. 5/1, Yerevan-14, Armenia. Email: tauret@arminco.com

**) INSERM Unit 592/Universite Piere et Marie Curie - Laboratoire de Physiopathologie Cellulaire et Moleculaire de la Retine, Hopital St.Antoine, Bat. Kourilsky 184, Rue du Fbg St. Antoine, 75571 Paris Cedex 12, France. Email: leveilla@st-antoine.inserm.fr

Among inherited retinal degenerations most dominant are rod-cone dependent forms, hence for curving or preventing retina related blindness efforts are directed to rescue photoreceptors. A novel protein derived from rods is of special interest because of its potential to rescue cone cells [1]. This thioredoxin-like protein was named - rod derived cone viability factor (RdCVF) [1]. By light immunohistochemistry RdCVF is mostly localized in region involving rod outer and inner segments (ROS \& RIS) [1]. Meantime fine distribution of RdCVF has no yet clarified. Namely for this purpose current study was undertaken.

Initially RdCVF-C (PG-61) rabbit polyclonal antibodies and gold colloid (average $20 \mathrm{~nm}$ size) were prepared by method described earlier [1,2]. Antibody and colloidal gold conjugation was carried by method described previously [3]. Per one gold particle about 5-45 molecules PG-61 conjugated depending from diameter of colloid. Dark adapted wild rabbits Oryctolagus niger were used in this study. Incubation solution was made on the base described in [4]. 10 different combinations were used in this study for immunohistochemical reaction between RdCVF and antibody-gold conjugate; including development of ultra thin sections of isolated retina fixed with $1.25 \%$ Glutaraldeyde then treated with or without $\mathrm{NH}_{4} \mathrm{Cl}$ or Triton $\mathrm{X}-100$ or block staining with the same variations, with or without $\mathrm{OsO}_{4}$ fixation, method described in literature [5]. Clear results were obtained after additional staining, with PG-61 conjugated with colloidal gold, of ultra thin sections of block stained samples, treated before embedding with $0.2 \mathrm{M} \mathrm{NH}_{4} \mathrm{Cl}$ and $0.1 \%$ Triton $\mathrm{X}-100$. Homogenously distributed reaction product mainly was observed in upper part of outer nuclear layer in the RIS region, rarely in ROS region and in very few cases in inner nuclear layer. The results of this preliminary study is in agreement with previous results [1] and evidence RdCVF localization mostly in RIS region.

\section{References}

1. Levellard T.,Mohand-Said S., Lorentz O., Hicks D., Fintz A.C., Clerin E., Simonutti M., Forster V., Cavusoglu N., Chalmel F.,Dolle P., Poch PO., Lambrou G., Sahel J.A., 2004, Identification and characterization of roddrived cone viability factor Nat. Genet. 36:755-759

2. Frens G., 1973, Controlled nucleation for the regulation of the particle size in monediperse gold suspesion. Nature Phys. Sci. 241:20-24.

3. Leuvering J.H.W 1980, Sol particle immunoassay. J. Immunoassay 1:77-91

4. Pierno S,, De Luca A.,, Huxtable R.J., Conte Camerino D.,1994, Dual effects of taurine on membrane ionic conductances of rat skeletal muscle fibres. Adv Exp. Med. Biol , 359:217-224

5. Immunolabeling for electrone microscopy 1985, Ed. by Polack J.M., Varndell I.M. Elsevier Amst., NY Oxford 


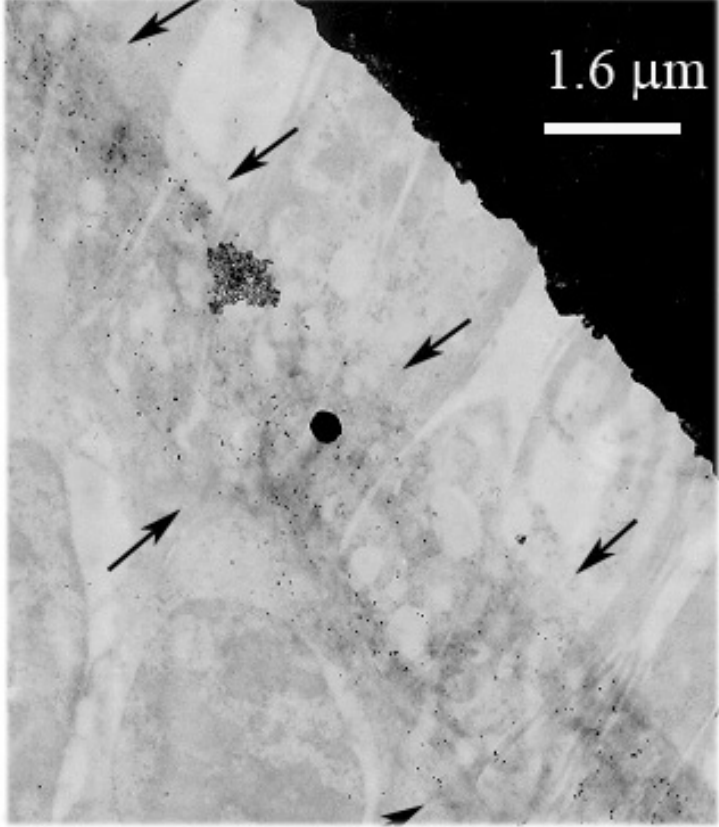

Figure $1 \mathrm{ONL}$ and RIS region Arrows. indicate reaction product in distal RIS region

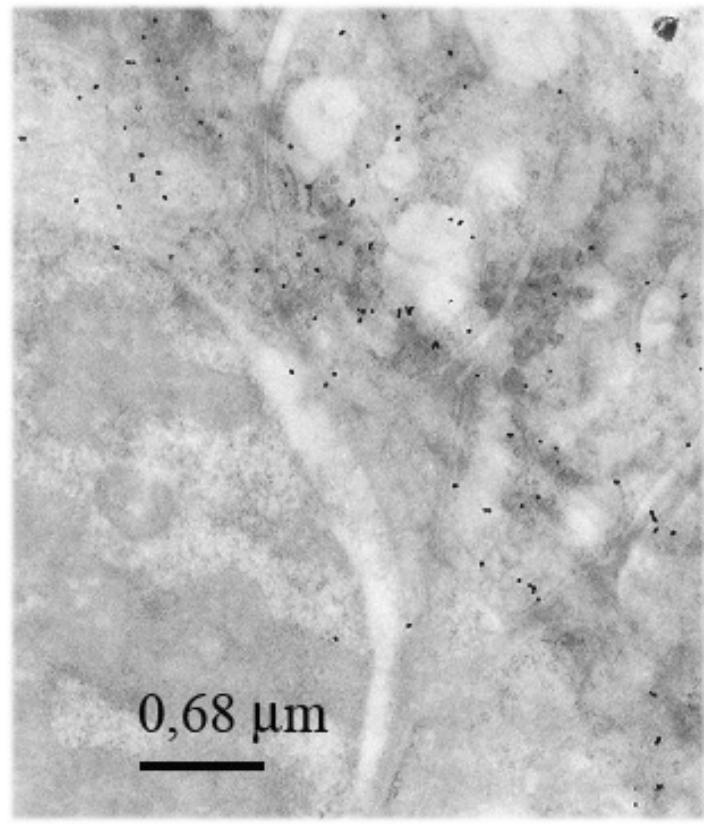

Figure 3 Reaction product in distal RIS region upper to nucleous..

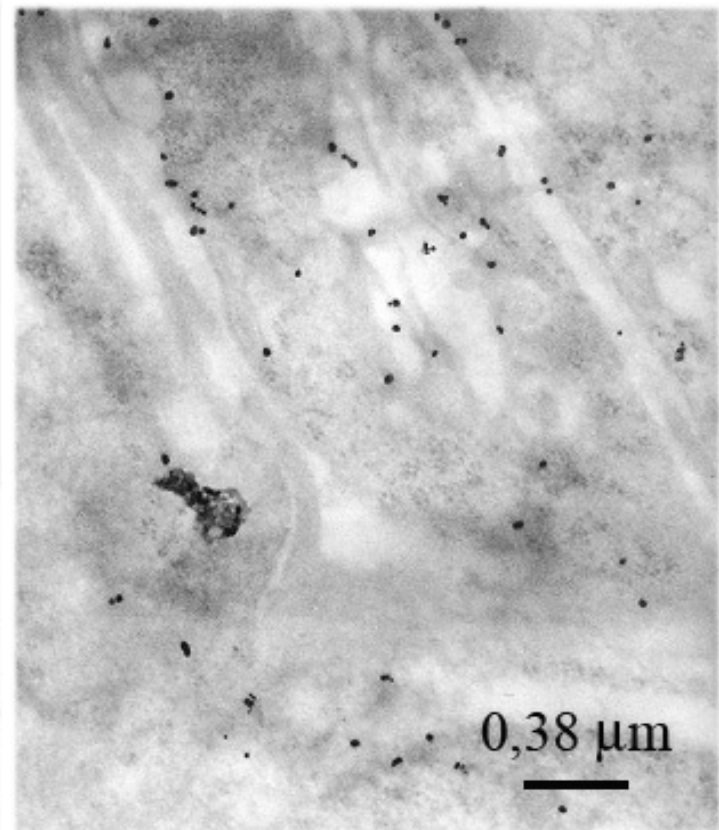

Figure 2. Fragment from RIS region

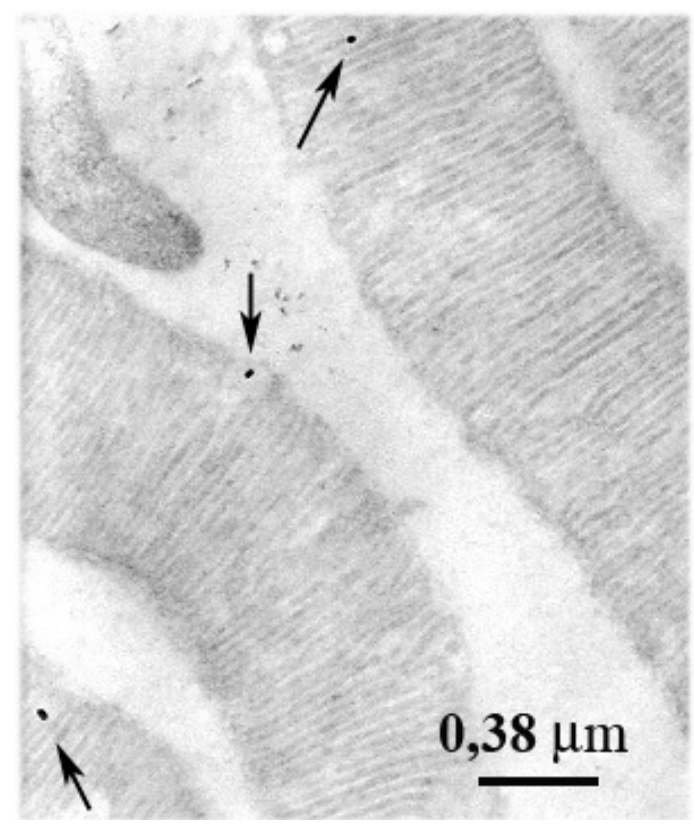

Figure 4 Rare reaction product on ROS,

Acknowlegement: This study was carried on TEM Crio CM-10 granted by FEI company. 